\title{
Histopathological evaluation of the effect of locally administered strontium on healing time in mandibular fractures: An experimental study
}

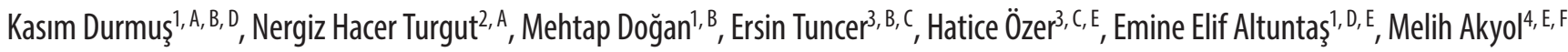 \\ ${ }^{1}$ Department of Otolaryngology, Faculty of Medicine, Cumhuriyet University, Sivas, Turkey \\ ${ }^{2}$ Department of Pharmacology, Faculty of Pharmacy, Cumhuriyet University, Sivas, Turkey \\ ${ }^{3}$ Department of Pathology, Faculty of Medicine, Cumhuriyet University, Sivas, Turkey \\ ${ }^{4}$ Department of Dermatology, Faculty of Medicine, Cumhuriyet University, Sivas, Turkey \\ A - research concept and design; $B$ - collection and/or assembly of data; $C$ - data analysis and interpretation; \\ $D$ - writing the article; $E$ - critical revision of the article; $F$ - final approval of article
}

\section{Address for correspondence \\ Kasım Durmuş}

E-mail: kasimdurmus58@gmail.com

Funding sources

None declared

Conflict of interest

None declared

Received on August 5, 2015

Revised on May 4, 2016

Accepted on September 30, 2016

\begin{abstract}
Background. Mandibular fractures are the most common facial fractures. They can be treated by conservative techniques or by surgery. The authors hypothesized that the application of a single local dose of strontium chloride would accelerate the healing of subcondylar mandibular fractures, shorten the recovery time and prevent complications.

Objectives. The aim of the present pilot study was to evaluate the effects of a single local dose of strontium chloride on the healing of subcondylar mandibular fractures in rats.

Material and methods. This randomized experimental study was carried out on 24 male Wistar albino rats. The rats were randomly divided into 3 groups: experimental group 1, receiving 3\% strontium chloride; experimental group 2, receiving 5\% strontium chloride; and the control group. A full thickness surgical osteotomy was created in the subcondylar area. A single dose of strontium solution (0.3 cc/site) was administered locally by injection on the bone surfaces of the fracture line created. Nothing was administered to the control group. The mandibles were dissected on postoperative day 21. The fractured hemimandibles were submitted to histopathological examination.

Results. The median bone fracture healing score was 9 (range: 7-9) in experimental group 1; 8 (range: 7-10) in experimental group 2; and 7.50 (range: 7-8) in the control group. When the groups were compared in terms of bone healing scores, there was a statistically significant difference between experimental group 1 and the control group $(p<0.05)$.

Conclusions. This study is the first to show that local strontium may have positive effects on the healing of subcondylar mandibular fractures. In the authors' opinion, $3 \%$ strontium was beneficial for accelerating facial skeleton consolidation and bone regeneration in rat subcondylar mandibular fractures. This treatment procedure may be combined with closed fracture treatment or a conservative approach.
\end{abstract}

Key words: strontium chloride, fracture healing, subcondylar mandibular fractures

DOI

10.17219/acem/65477

\section{Copyright}

Copyright by Author(s)

This is an article distributed under the terms of the

Creative Commons Attribution Non-Commercial License

(http://creativecommons.org/licenses/by-nc-nd/4.0/) 
Mandibular fractures are the most common facial fractures in facial trauma and account for $23-97 \%$ of all facial fractures. ${ }^{1}$ In the mandible and maxillofacial region, fractures of the mandibular condylar processes, which account for $25-35 \%$ of all mandibular fractures, are the most common fractures. ${ }^{2}$

Re-establishing anatomy, providing stabilization and restoring functionality with the least morbidity are the therapeutic targets of condylar fracture management. ${ }^{3}$ These fractures can be treated using a conservative technique (closed reduction) or by surgery., 2,4 Generally, in the treatment of subcondylar mandibular fractures, external fixation with arch bars is performed for 3 weeks in non-displaced fractures (except when open reduction and internal fixation is indicated) and 6 weeks in displaced fractures.

Closed treatment requires a period of maxillomandibular fixation, followed by active physiotherapy. The closed reduction method may lead to complications such as pain, arthritis, an open bite, deviation of the mandible on opening, inadequate restoration of the vertical height of the ramus leading to malocclusion, and ankyloses in the long term.

Strontium salts are elements acting as secondary messengers and competing with calcium in the organism. Strontium is structurally similar to calcium and helps build bone. The positive effect of strontium on bone formation has been known since $1950{ }^{6}$ Systemic administration of strontium has been reported to have a positive effect on bone healing by increasing osteoblastic activity and decreasing osteoclastic activity. ${ }^{7}$

The aim of the present pilot study was to evaluate the effects of a single local dose of strontium chloride on the healing of subcondylar mandibular fractures in rats. The authors hypothesized that applying a single local dose of $3 \%$ or $5 \%$ strontium chloride (SC) would accelerate the healing of subcondylar mandibular fractures, shorten the recovery time and prevent complications.

\section{Material and methods}

\section{The experimental animals}

The study protocol was approved by the Institutional Review and Animal Ethics Committee of the Cumhuriyet University School of Medicine (Sivas, Turkey), and the study was conducted according to "Guide for the Care and Use of Laboratory Animals". ${ }^{8}$

In this study, a randomized experimental protocol was used. The study was carried out on 24 male Wistar albino rats, aged 16-18 weeks, with an average body weight of $230 \pm 10 \mathrm{~g}$. The rats were randomly divided into 3 groups: experimental group 1 , receiving $3 \% \mathrm{SC}(0.3 \mathrm{cc} / \mathrm{site}$, $\mathrm{n}=8)$; experimental group 2 , receiving $5 \% \mathrm{SC}(0.3 \mathrm{cc} /$ site, $\mathrm{n}=8)$; and the control group $(\mathrm{n}=8)$.
The rats were housed in standard laboratory conditions (12 h light/dark cycles, $24 \pm 2^{\circ} \mathrm{C}, 35-60 \%$ humidity). Because of the broken jaws, all the animals were fed only soft food and water during the first 7 days of the experiment. The animals resumed normal diets (a standard laboratory diet and drinking water) after the $1^{\text {st }}$ week.

\section{The drug and chemicals}

Strontium chloride was obtained from Sigma Chemical Co. (St. Louis, USA). This reagent was dissolved in saline and the purity of all the chemical reagents was at least analytical grade. The strontium solution $(0.3 \mathrm{cc} / \mathrm{site})$ was administered locally by injection on the bone surfaces of the fracture lines created.

\section{Operation procedure and study protocol}

The animals were anesthetized with intraperitoneal injections $(7.5 \mathrm{mg} / \mathrm{kg})$ of ketamine (Ketalar ${ }^{\circledR}$, Pfizer Turkey, Istanbul, Turkey) and intramuscular injections $(6 \mathrm{mg} / \mathrm{kg})$ of xylazine (Rompun ${ }^{\circledR}$, Bayer, Istanbul, Turkey). In each rat, the right buccal area was shaved and prepared with an antiseptic solution (povidone iodine). Following an approx. $10 \mathrm{~mm}$ incision made along the inferior border of the mandible and the division of the masseter muscle, a full thickness surgical osteotomy was created using mosquito forceps in the subcondylar area, which was confirmed by condyle fragment mobility. Hemostasis was induced both on the fracture line and the connected soft tissues, and a single dose of $3 \% \mathrm{SC}(0.3 \mathrm{cc} / \mathrm{site})$ was administered by injection to experimental group $1(\mathrm{n}=8)$; and $5 \% \mathrm{SC}(0.3 \mathrm{cc} /$ site) was administered to experimental group $2(\mathrm{n}=8)$. Nothing was administered to the control group $(\mathrm{n}=8)$.

The wounds were not syringed and no debris was removed. Finally, the skin flaps were replaced and sutured. All the rats were administered intramuscular penicillin injections during the first 3 days after the operation.

After postoperative day 21, the animals were euthanized with intraperitonial injections of pentothal sodium $(200 \mathrm{mg} / \mathrm{kg})$. The mandibles were then dissected, all soft tissues were removed, and the fractured hemimandibles were submitted for histopathological examination.

\section{Histopathological examinations}

The histologic analyses were performed by 2 pathologists (HO, ET) who were blind to the samples. All the tissue examples were immediately fixed in $10 \%$ formalin. After fixation, the specimens were kept in 10\% nitric acid. Decalcification was complete in 4 days and the specimens were embedded in paraffin. The specimens were cut in the sagittal sections into 5 - $\mu$ m-thick sections, transferred to slides for conventional hematoxylin-eosin (H\&E) staining and examined by light microscopy (Eclipse 80İ, Nikon Instruments Inc., Tokyo, Japan). A digital cam- 
Table 1. Histological scoring system for the evaluation of fracture healing

\begin{tabular}{|c|c|}
\hline Score & Histological findings in the fracture zone \\
\hline 1 point & fibrous tissue \\
\hline 2 points & mainly fibrous tissue and small amounts of cartilage tissue \\
\hline 3 points & equal amounts of fibrous and cartilage tissue \\
\hline 4 points & entirely cartilage tissue \\
\hline 5 points & mainly cartilage tissue and small amounts \\
\hline 6 points & equal amounts of cartilage tissue and immature bone \\
\hline 7 points & significant immature bone and small amounts of cartilage \\
\hline 8 points & entirely immature bone \\
\hline 9 points & immature bone and small amounts of mature bone \\
\hline 10 points & mature (lamellar) bone \\
\hline
\end{tabular}

era and auxiliary equipment (Nikon USB (H) EXT 1/0, Nikon Instruments Inc., Tokyo, Japan) were used with the microscope to obtain digital images of the sections.

The amount of the ossification for each section was scored on a grading scale ranging from 1 point (fibrous tissue) to 10 points (mature bone), as described by Huo and Troiano (Table 1). ${ }^{9}$

\section{Statistical analysis}

The data were analyzed using SPSS software for Windows (v. 22.0, SPSS Inc., Chicago, USA). Sections of all the specimens stained with hematoxylin-eosin were scored. The average scores were calculated for both groups and the differences between the groups were analyzed statistically. The data was expressed as mean, median and minimummaximum. All of the group differences were analyzed with the Kruskal-Wallis test to investigate the cause of the discrepancy $(\mathrm{p}<0.05)$ encountered with the Mann-Whitney U test.

\section{Results}

Three days after surgery, 2 rats in experimental group 1 , 1 rat in the control group and 2 rats in experimental group 2 died due to dehydration and nutritional prob-
Fig. 1. A histological section from the experimental group 1 treated with 3\% SC; immature (woven) bone and small amounts of mature bone formation (score: 9 ; HE; $\times 200$ )

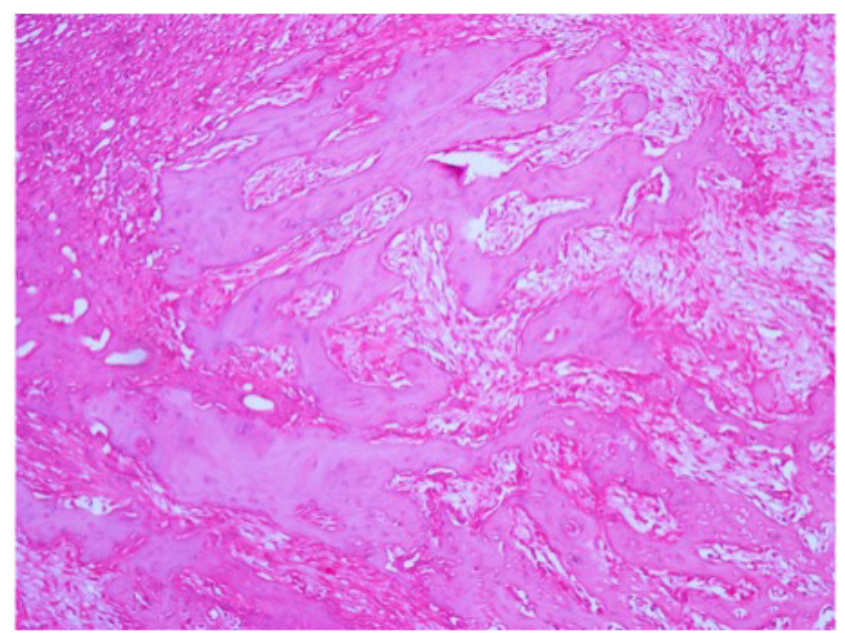

Fig. 2. A histological section from the control group; significant immature (woven) bone and small amounts of cartilage formation (score: 7; HE; $\times 100$ )

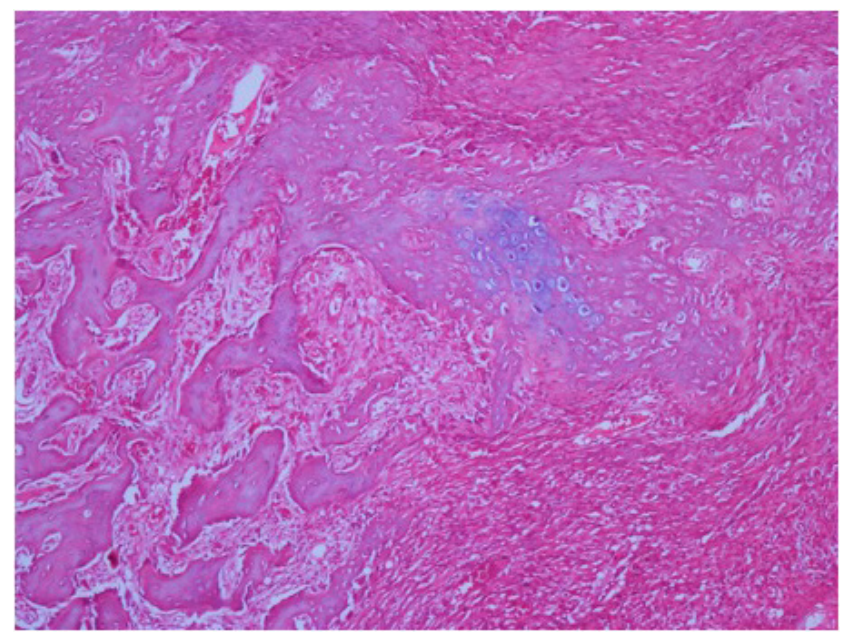

lems. Thus, no histological examination was performed on these rats. As a result, 6 rats in experimental group 1, 7 rats in experimental group 2, and 6 rats in the control group were included in the study. The application was well tolerated by all the rats and there was no significant weight loss until the day they were sacrificed.

With regard to bone fracture healing, the histological scores of all the specimens stained with hematoxylin-eosin are given in Table 2. Histopathological examination revealed immature (woven) bone and small amounts of ma-

Table 2. Histological scores for fracture healing in all three groups

\begin{tabular}{|c|c|c|c|c|c|c|c|}
\hline Groups & Min & Max & Median & Mode & Mean & p-value (KW) & $\mathrm{p}$-value (MW) \\
\hline Experimental group $1(n=6)$ & 7 & 9 & 9 & 9 & $8.67 \pm 0.82$ & \multirow{3}{*}{$0.014^{*}$} & $1.000^{\mathrm{a}}$ \\
\hline Experimental group $2(n=7)$ & 7 & 10 & 8 & 10 & $8.57 \pm 1.40$ & & $0.234^{b}$ \\
\hline Control group $(n=6)$ & 7 & 8 & 7.5 & 7 & $7.50 \pm 0.55$ & & $0.026^{c}$ \\
\hline
\end{tabular}

* - differences in all groups were analyzed by the Kruskal-Wallis test; a - experimental groups 1 and 2 were analyzed by the Mann-Whitney $U$ test; b - experimental group 2 and control group were analyzed by the Mann-Whitney $\mathrm{U}$ test; $\mathrm{c}$ - experimental group 1 and control group were analyzed by the Mann-Whitney $\mathrm{U}$ test. 
ture bone formation in experimental group 1 (Fig. 1), and significant immature (woven) bone and small amounts of cartilage formation in the control group (Fig. 2).

The median bone fracture healing score was 9 (range: 7-9). There was immature bone and small amounts of mature bone in experimental group 1, with a median healing score of 9 (range: 7-9); completely immature (woven) bone in experimental group 2 , with a median healing score of 8 (range: 7-10); and significant immature (woven) bone and small amounts of cartilage in the control group, with a median healing score of 7.50 (range: 7-8). When the groups were compared in terms of bone healing scores, there were no statistical differences between experimental groups 1 and 2 or between the experimental group 2 and the control group, while there was a statistically significant difference between the experimental group 1 and the control group $(\mathrm{p}<0.05)$.

\section{Discussion}

This study was designed to investigate the impact of a single application of $3 \%$ and $5 \%$ SC on bone healing and the histologic characteristics of the new bone induced by these applications. The results showed a statistically significant difference between the controls and the rats treated with a single dose of $3 \% \mathrm{SC}$ in terms of mean bone fracture healing score. It was remarkable that there were rats with mature (lamellar) bone formation in the group treated with 1 application of 5\% SC. However, the controls and the group treated with 5\% SC did not show any statistically significant difference in terms of bone healing scores.

Strontium, which has a strong affinity for hydroxyapatite, is an alkaline metal cation. ${ }^{10}$ The similarity of strontium to calcium allows strontium to be incorporated into the mineral phase of bone. The positive effect of strontium on bone homeostasis was shown in some studies conducted in the 1950 s. $^{6}$

Awareness of the biological role of strontium has increased in recent years. ${ }^{11,12}$ Physiological bone regeneration, a coordinated process, is maintained by boneforming osteoblasts and bone-resorbing osteoclasts. The 2 factors produced by osteoblasts forming the bone: receptor activator NF- $\mathrm{kB}$ ligand (RANKL) and osteoprotegerin (OPG) control the activity and differentiation of osteoclasts. ${ }^{14-16}$ The bone-building action of strontium works by down-regulating osteoclastogenesis, modulating the RANKL/OPG balancing system. ${ }^{7,13}$ These effects of strontium have attracted the attention of many researchers, and many studies have been conducted on the local and systemic use of strontium. It has been reported that applying strontium systematically increases peri-implant bone volume and implant pullout ability in animal subjects with bone-integrated implants. ${ }^{17,18}$ It has also been demonstrated that bioactive glass and glass-ceramics that include local strontium show biocompatibility. ${ }^{19-22}$
The positive effects of strontium on peri-implant bone formation have led researchers to develop various methods of local strontium administration. These methods include strontium-substituted hydroxyapatite implants, modification of metal oxide layers with a strontium-containing salt, generation of strontium titanate nanotubes on the surfaces of metal implants, bioactive glass comprising strontium, and incorporation of strontium into metal oxide layers on implant surfaces. ${ }^{23-27}$

Strontium that is incorporated into bone cements has been found to improve bone formation and reduce bone resorption invivo. ${ }^{28}$ Sabareeswaran etal.investigated thebioactive fixation of strontium-containing glass ceramics and found out that it led to osseointegration during shortterm implementation. ${ }^{29}$

Schumacher et al. investigated the effect of strontium(II) released from calcium phosphate bone cement on primary human mesenchymal stem cells and reported that it could be useful for local therapy, particularly in osteoporotic bone. ${ }^{30}$

Al-Duliamy et al. studied the effects of locally injected strontium on the anchoring unit of experimental relapsed tooth movement in a rat model. They noted that the strontium injections led to significant inhibition of both tooth movement and relapse movement, and that "histological examinations showed that strontium enhanced the number of osteoblasts and reduced the number of osteoclasts". 31

Forsgren et al. showed that incorporating strontium into the surfaces of orthopedic and dental implants accelerated bone healing. ${ }^{24}$ Hao et al. found that the use of strontium hydroxyapatite and alginate in an injectable in situ gel-forming system resulted in shorter healing times in a rat calvarial model compared with conventional graft surgery, and that the animals showed no signs of inflammation. ${ }^{32}$ They also stated that this in situ gelforming system could be an advantageous and minimally invasive process for local bone augmentation.

\section{Conclusions}

Treating subcondylar fractures is a controversial issue. ${ }^{33}$ It can be conducted in 2 different ways: by conservative methods or surgically. For decades, closed reduction has been the preferred treatment. However, closed treatment requires varying periods of maxillomandibular fixation (up to 4 weeks) and involves the risk of long-term complications such as pain, ankylosis, internal derangement of the temporomandibular joint, as well as inadequate restoration of the vertical height of the ramus. ${ }^{34}$ Therefore, in recent years, there has been an increase in the number of studies indicating that surgery should be the preferred treatment in subcondylar mandibular fractures. The controversy over the treatment of condylar fractures is based on 3 main factors: 1) the age of the frac- 
ture incidence; 2) the pattern of deviation of the fracture; and 3 ) the level of the fracture. In some cases, a conservative approach should still be the preferred treatment.

With this in mind, the current authors employed single applications of 3\% and 5\% strontium, thinking it would shorten the treatment time in cases undergoing conservative treatment. In the studies mentioned above, local administration of strontium has been effective in orthopedics and dental implants. Similarly, the current study showed that $3 \%$ strontium applied over the fracture surface in the mandible accelerated healing histopathologically.

This study is the first to show that local strontium may have positive effects on healing subcondylar mandibular fractures. A local application of 3\% strontium chloride hexahydrate has no adverse effect, and accelerates facial skeleton consolidation and bone regeneration. The authors suggest that a combination of strontium chloride hexahydrate and conventional therapeutic approaches may shorten the healing time of subcondylar mandibular fractures in rats.

\section{References}

1. Fernández JR, Gallas $M$, Burguera $M$, Viaño JM. A three-dimensional numerical simulation of mandible fracture reduction with screwed miniplates. J Biomech. 2003;36(3):329-337.

2. Dayi E, Omezli MM. Review of biomechanical experimental studies on different plating techniques of mandibular condyle fractures. Ann Maxillofac Surg. 2011;1(1):48-52. doi: 10.4103/2231-0746.83157.

3. Lauer $G$, Haim $D$, Proff $P$, et al. Plate osteosynthesis of the mandibular condyle. Ann Anat. 2007;189:412-417.

4. Seemann R, Schicho K, Reichwein A, Eisenmenger G, Ewers R, Wagner A. Clinical evaluation of mechanically optimized plates for the treatment of condylar process fractures. Oral Surg Oral Med Oral Pathol Oral Radiol Endod. 2007;104:1-4.

5. Alkan A, Metin M, Muglali M, Ozden B, Celebi N. Biomechanical comparison of plating techniques for fractures of the mandibular condyle. Br J Oral Maxillofac Surg. 2007;45:145-149.

6. Shorr E, Carter AC. The usefulness of strontium as an adjuvant to calcium in the remineralization of the skeleton in man. Bull Hosp Jt Dis. 1952;13:56-66.

7. Yang F, Yang D, Tu J, Zheng Qixin, Cai L, Wang L. Strontium enhances osteogenic differentiation of mesenchymal stem cells and in vivo bone formation by activating wnt/catenin signaling. Stem Cells. 2011;29:981-991.

8. Clark JD, Gebhart GF, Gonder JC, Keeling ME, Kohn DF. Special report: The 1996 Guide for the Care and Use of Laboratory Animals. ILAR J. 1997;38(1):41-48.

9. Huo MH, Troiano NW. The influence of ibuprofen on fracture repair: Biomechanical, biochemical, histologic, and histomorphometric parameters in rats. J Orthop Res. 1991;9:383-390.

10. Pors Nielsen S. The biological role of strontium. Bone. 2004;35(3):583-588.

11. Meunier PJ, Roux C, Ortolani S, et al. Effects of long-term strontium ranelate treatment on vertebral fracture risk in postmenopausal women with osteoporosis. Osteoporosis International. 2009;20:1663-1673.

12. Reginster JY, Felsenberg D, Boonen S, et al. Effects of long-term strontium ranelate treatment on the risk of nonvertebral and vertebral fractures in postmenopausal osteoporosis: Results of a fiveyear, randomized, placebo-controlled trial. Arthritis Rheum. 2008;58(6):1687-1695. doi: 10.1002/art.23461.

13. Saidak Z, Marie PJ. Strontium signaling: Molecular mechanisms and therapeutic implications in osteoporosis. Pharmacol Ther. 2012;136(2):216-226. doi:10.1016/j.pharmthera.2012.07.009.
14. Hofbauer LC, Khosla S, Dunstan CR, et al. The roles of osteoprotegerin and osteoprotegerin ligand in the paracrine regulation of bone resorption. J Bone Miner Res. 2000;15:2-12.

15. Schwarz EM, O'Keefe RJ. Breakthrough in bone: The molecular mechanism of osteocladosteoblast coupling revealed. Curr Opni Orthop. 2000;1:329-335.

16. Teitelbaum SL. Bone resorption by osteoclasts. Science. 2000:289:1504-1508.

17. Maïmoun L, Brennan TC, Badoud I, Dubois-Ferriere V, Rizzoli R, Ammann P. Strontium ranelate improves implant osseointegration. Bone. 2010;46:1436-1441.

18. Li Y, Li X, Song G, Chen K, Yin G, Hu J. Effects of strontium ranelate on osseointegration of titanium implant in osteoporotic rats. Clin Oral Implants Res. 2011;23:1038-1044.

19. Ravi ND, Balu R, Sampath Kumar TS. Strontium-substituted calcium deficient hydroxyapatite nanoparticles: Synthesis, characterization, and antibacterial properties. J Am Ceram Soc. 2012;95(9): 2700-2708.

20. Goel A, Rajagopal RR, Ferreira JM. Influence of strontium on structure, sintering and biodegradation behaviour of $\mathrm{CaO}-\mathrm{MgO}-\mathrm{SrO}-$ $\mathrm{SiO}_{2}-\mathrm{P}_{2} \mathrm{O}_{5}-\mathrm{CaF}_{2}$ glasses. Acta Biomater. 2011;7(11):4071-4080.

21. Vestermark MT, Hauge EM, Soballe K, Bechtold JE, Jakobsen T, Baas J. Strontium doping of bone graft extender. Acta Orthop. 2011;82(5):614-621.

22. Hamdy NA. Strontium ranelate improves bone microarchitecture in osteoporosis. Rheumatology. 2009;48(suppl 4):9-13.

23. Fu DL, Jiang QH, He FM, Yang GL, Liu L. Fluorescence microscopic analysis of bone osseointegration of strontium-substituted hydroxyapatite implants. J Zhejiang Univ Sci B. 2012;13:364-371.

24. Forsgren J, Engqvist $\mathrm{H}$. A novel method for local administration of strontium from implant surfaces. J Mater Sci Mater Med. 2010; 21(5):1605-1609. doi: 10.1007/s10856-010-4022-8.

25. Zhao $L$, Wang $H$, Huo $K$, et al. The osteogenic activity of strontium loaded titania nanotube arrays on titanium substrates. Biomaterials. 2013;34:19-29.

26. Gentleman E, Fredholma YC, Jell G, et al. The effects of strontium-substituted bioactive glasses on osteoblasts and osteoclasts in vitro. Biomaterials. 2010;31:3949-3956.

27. Park JW, Kim Y, Jang J, Song H. Positive modulation of osteogenesis- and osteoclastogenesis-related gene expression with strontium-containing microstructured $\mathrm{Ti}$ implants in rabbit cancellous bone. J Biomed Mater Res A. 2013;101:298-306.

28. Kokesch-Himmelreich J, Schumacher M, Rohnke M, Gelinsky M, Janek J. ToF-SIMS analysis of osteoblast-like cells and their mineralized extracellular matrix on strontium enriched bone cements. Biointerphases. 2013;8(1):17. doi: 10.1186/1559-4106-8-17.

29. Sabareeswaran A, Basu B, Shenoy SJ, Jaffer Z, Saha N, Stamboulis A. Early osseointegration of a strontium containing glass ceramic in a rabbit model. Biomaterials. 2013;34(37):9278-9286. doi: 10.1016/j.biomaterials.2013.08.070.

30. Schumacher M, Lode A, Helth A, Gelinsky M. A novel strontium(II)modified calcium phosphate bone cement stimulates humanbone-marrow-derived mesenchymal stem cell proliferation and osteogenic differentiation in vitro. Acta Biomater. 2013;9(12):95479557. doi: 10.1016/j.actbio.2013.07.027.

31. Al-Duliamy MJ, Ghaib NH, Kader OA, Abdullah BH. Enhancement of orthodontic anchorage and retention by the local injection of strontium: An experimental study in rats. Saudi Dent J. 2015;27(1):22-29. doi: 10.1016/j.sdentj.2014.08.001.

32. Hao J, Chou J, Kuroda S, Otsuka M, Kasugai S, Lang NP. Strontium hydroxyapatite in situ gel-forming system: A new approach for minimally invasive bone augmentation. Clin Oral Implants Res. 2015;26(5):581-585. doi: 10.1111/clr.12446.

33. Lee $\mathrm{HC}$, Kang DH, Koo SH, et al. Outcome of open reduction via retromandibular approach for mandibular subcondyle fracture. J Korean Soc Plast Reconstr Surg. 2005;32:739-743.

34. Jang JY, Kang DH. Comparison study of open reduction and closed reduction in treatment of mandibular subcondylar fractures. J Korean Cleft Palate-Craniofac Assoc. 2008;9:51-54. 